\title{
Short communication: Heritability of methane production and genetic correlations with milk yield and body weight in Holstein-Friesian dairy cows
}

\author{
I. S. Breider, ${ }^{1,2}$ E. Wall, ${ }^{2}$ and P. C. Garnsworthy ${ }^{1 *}$ \\ ${ }^{1}$ School of Biosciences, University of Nottingham, Sutton Bonington Campus, Loughborough LE12 5RD, United Kingdom \\ ${ }^{2}$ Department of Animal and Veterinary Sciences, Scotland's Rural College, Edinburgh EH25 9RG, United Kingdom
}

\section{ABSTRACT}

Greenhouse gases originating from the dairy sector, including methane $\left(\mathrm{CH}_{4}\right)$, contribute to global warming. A possible strategy to reduce $\mathrm{CH}_{4}$ production is to use genetic selection. This requires genetic parameters for $\mathrm{CH}_{4}$ production and correlations with production traits. Data were available on 184 Holstein-Friesian cows. Methane production was measured in the milking robot during milking from December 2009 to April 2010. In total 2,456 observations for $\mathrm{CH}_{4}$ production were available. Milk yield (MY) and body weight (BW) were obtained at every milking from November 2008 to October 2010. In total 4,567 observations for milk yield and 4,570 observations for BW were available. Restricted maximum likelihood, using random regression models, was used to analyze the data. Heritability (standard error given in parentheses) for $\mathrm{CH}_{4}$ production ranged from $0.12(0.16)$ to $0.45(0.11)$, and genetic correlations with MY ranged from $0.49(0.12)$ to 0.54 (0.26). The positive genetic correlation between $\mathrm{CH}_{4}$ production and milk yield indicates that care needs to be taken when genetically selecting for lower $\mathrm{CH}_{4}$ production, to avoid a decrease in MY at the animal level. However, this study shows that $\mathrm{CH}_{4}$ production is moderately heritable and therefore progress through genetic selection is possible.

Key words: methane production, climate change, heritability, genetic correlation

\section{Short Communication}

Greenhouse gases, including methane $\left(\mathrm{CH}_{4}\right)$, play an important role in global warming. Methane has 28 times the global warming potential of $\mathrm{CO}_{2}$ (Myhre et al., 2013). The dairy supply chain produces $20 \%$ of the global livestock-sector greenhouse gas emissions, and $46.5 \%$ of the total greenhouse gas emission of the dairy

\footnotetext{
Received October 27, 2018.

Accepted April 4, 2019.

*Corresponding author: Phil.Garnsworthy@nottingham.ac.uk
}

supply chain is from enteric $\mathrm{CH}_{4}$ (Gerber et al., 2013). Therefore, reducing $\mathrm{CH}_{4}$ production from dairy cattle will have an important influence on total $\mathrm{CH}_{4}$ production. One possible strategy is to use genetic selection to reduce $\mathrm{CH}_{4}$ production. Before genetic selection for $\mathrm{CH}_{4}$ production can be introduced, however, genetic parameters of $\mathrm{CH}_{4}$ production and correlations with production traits are required. Currently, few estimates of heritability and correlations with related traits are available. Pickering et al. (2015) found a heritability of 0.05 (SE 0.07) for $\mathrm{CH}_{4}$ production $(\mathrm{mg} / \mathrm{kg}$ ), obtained using a laser methane detector, but this estimate was not significant. Lassen and Løvendahl (2016) found a heritability of 0.21 (SE 0.06) for $\mathrm{CH}_{4}$ production (g/d), measured using Fourier-transform infrared spectroscopy to measure $\mathrm{CH}_{4}$ production during milking. Pszczola et al. (2017) found an average heritability of 0.27 (average $\mathrm{SE}$ 0.09) for $\mathrm{CH}_{4}$ production (g/d), measured using the same technique. These studies are a first indication that $\mathrm{CH}_{4}$ production in dairy cattle is heritable. However, heritability of $\mathrm{CH}_{4}$ production is not yet fully established, and correlations between $\mathrm{CH}_{4}$ production and related traits such as milk yield (MY) and BW are unknown. Except for Pszczola et al. (2017), data sets used in previous studies are generally point estimates in time. For the current study daily $\mathrm{CH}_{4}$ measurements on the herd were available over a longer continuous period than was used in the study by Pszczola and colleagues (2017).

Multiple definitions are currently in use for $\mathrm{CH}_{4}$ emission as a phenotype, such as $\mathrm{CH}_{4}$ production $(\mathrm{g} / \mathrm{d}$ or $\mathrm{L} / \mathrm{d}$ ), $\mathrm{CH}_{4}$ intensity ( $\mathrm{g} / \mathrm{kg}$ of product or $\mathrm{L} / \mathrm{kg}$ of product), and $\mathrm{CH}_{4}$ yield ( $\mathrm{g} / \mathrm{kg}$ of DMI or L/ $\mathrm{kg}$ of DMI; Herd et al., 2013). Although $\mathrm{CH}_{4}$ intensity and $\mathrm{CH}_{4}$ yield are definitions more relevant to food production for human consumption, both are ratio traits. For breeding purposes, inclusion of ratio traits in selection indexes is inappropriate. Because multiple variables contribute to ratio traits, the selection response can become unpredictable (Basarab et al., 2013), and the error variance of the trait is likely to increase (Berry and Crowley, 2013). Furthermore, use of ratio traits 
will cause the absolute differences between animals to be lost (Pryce et al., 2014). Therefore, the objectives of this study were to estimate (1) heritability of $\mathrm{CH}_{4}$ production $(\mathrm{g} / \mathrm{d})$, measured over a consecutive period of $5 \mathrm{mo}$, and (2) correlations between $\mathrm{CH}_{4}$ production (g/d) and MY (L/d) and BW (kg).

Animal work was conducted under authority of the UK Animal (Scientific Procedures) Act 1986, and approval was obtained from the University of Nottingham Animal Welfare and Ethical Review Body before commencement of the study.

Data were available on 184 Holstein-Friesian cows at the Nottingham University Dairy Centre (Sutton Bonington, UK; average milk yield $11,000 \mathrm{~kg} /$ cow per year). These cows were housed in a freestall barn under commercial conditions. Cows were born between May 2002 and June 2008. Average pedigree depth for animals with phenotypic data was 5 generations, ranging from 1 to 9 generations. Pedigree analysis was performed using R software package "pedantics" (Morrissey and Wilson, 2010). Animals with phenotypic data originated from 58 sires (10 sires missing) and 165 dams (no dams missing). Cows were managed as described by Garnsworthy et al. (2012b).

Methane production was measured in the milking robot during milking, as described by Garnsworthy et al. (2012a). Briefly, an air sampling tube was placed in the feeding bins inside the milking robots, sampling air at a rate of $1 \mathrm{~L} / \mathrm{min}$. These samples were analyzed using an infrared $\mathrm{CH}_{4}$ analyzer (Guardian Plus; Edinburgh Instruments Ltd., Livingston, UK). Results from this method agreed with results from measurements using respiration chambers $\left(\mathrm{R}^{2}=0.79, P<0.001\right.$; Garnsworthy et al., 2012a). Methane production measurements were taken at every milking from December 2009 to April 2010. For each cow, $\mathrm{CH}_{4}$ measurements at each milking in a day were averaged to a daily mean, and daily means were then averaged to a weekly mean $(\mathrm{g} / \mathrm{d})$.

In total 2,456 observations were available for $\mathrm{CH}_{4}$ production $(\mathrm{g} / \mathrm{d}, 18$ to 62 per week in milk, fewest toward the end of lactation). Observations for MY (L/d) and BW $(\mathrm{kg})$ were obtained at every milking from November 2008 to October 2010 and were also converted to weekly averages. In total 4,567 observations for MY (18 to 118 per week in milk, fewest toward the end of lactation) and 4,570 observations for BW (18 to 119 per week in milk, fewest toward the end of lactation) were available. Lactation number was limited to $\leq 4$, and week of lactation was limited to $\leq 52$. Pedigreebased analysis was used to estimate genetic parameters, including heritabilities, repeatabilities, and genetic and phenotypic correlations. As the traits of interest are largely longitudinal, random regression models were used to obtain variance components (Kirkpatrick et al., 1994; Mrode, 2005). A random regression function was used to account for changes in traits of interest at the population and animal (genetic) levels across time (Jamrozik and Schaeffer, 1997). Week of lactation was used as time covariate, and regression functions used were Legendre polynomials (Kirkpatrick et al., 1990). The order of the Legendre polynomial used at population level was set to 2 and was increased as long as the effect of the highest order was significant, with a maximum of order 5 . The order of the Legendre polynomial used at animal level was set to 1 , which was sufficient to model the deviation of the population curve.

The use of a random regression function using a Legendre polynomial of order 1 for the permanent environment was investigated. Although permanent environmental variance increased over lactation for MY in a bivariate analysis with BW, convergence problems occurred for the bivariate analysis between MY and $\mathrm{CH}_{4}$ production, and permanent environmental variance was constant over lactation for all other traits. To maintain comparability between bivariate analyses, therefore, a linear regression was used for the permanent environment instead of a Legendre polynomial.

To fit random regression models using week of lactation as vector of time covariates, sufficient observations across the whole lactation were needed at the population level. To ensure that the number of $\mathrm{CH}_{4}$ production observations was proportionate to the number of observations on MY and BW, only MY and BW observations for which a $\mathrm{CH}_{4}$ production observation was available within the same 4-week interval were kept in the data set. In practice this meant that 27 observations on MY and BW were removed from the data set. Bivariate random regression animal models were used to analyze the data set, as the size of the data set did not allow trivariate models to be used. Bivariate models were constructed based on univariate linear repeatability models and were constructed between each combination of the 3 traits. The Wald statistic was used to determine whether an effect was significant. Only significant fixed effects $(P<0.001)$ were kept in the model. Fixed effects for each trait were kept identical between bivariate models.

The following models were constructed:

$$
\begin{gathered}
M Y=\mu+\text { lact.WOL5 }+ \text { week }+\beta \times \text { age } \\
+ \text { WOL1.An }+P E+e, \\
B W=\mu+\text { WOL4 }+ \text { lact }+ \text { season }+ \text { week } \\
+\beta \times \text { age }+ \text { WOL1.An }+ \text { PE }+e, \text { and } \\
C H_{4}=\mu+\text { WOL1 + week }+ \text { WOL1.An }+P E+e,
\end{gathered}
$$


where $\mu$ is the intercept; $M Y=$ weekly average of milk yield observations; $B W=$ weekly average of body weight observations; $\mathrm{CH}_{4}=$ weekly observation of $\mathrm{CH}_{4}$ production observations for each cow for each week of lactation (WOL); lact. WOL5 = interaction between a vector of lactation number and Legendre polynomial order 5 on week of lactation as a fixed effect; WOL $4=$ Legendre polynomial order 4 on week of lactation as a fixed effect; $W O L 1=$ Legendre polynomial order 1 on week of lactation as a fixed effect; lact $=$ vector of lactation number as a fixed effect; week $=$ vector of the calendar week in which the measurements took place as a fixed effect; season $=$ vector of the calving season (March to May, June to August, September to November, and December to February) as a fixed effect; $\beta \times$ $a g e=$ covariate describing effect of age at measurement as a fixed effect; $W O L 1 . A n=$ interaction between Legendre polynomial order 1 on week of lactation and the additive genetic effect of animal as a random effect, $a$, where $a$ is normally distributed $N\left(0, \mathbf{I} \sigma_{a}^{2}\right)$ for which $\mathbf{I}$ is the identity matrix and $\sigma_{a}^{2}$ is the animal genetic variance; $P E=$ permanent environment effect as a random effect normally distributed $N\left(0, \mathbf{I} \sigma_{p e}^{2}\right)$ for which $\sigma_{p e}^{2}$ is the permanent environment variance; and $e=$ random residual normally distributed $N\left(0, \mathbf{I} \sigma_{e}^{2}\right)$ for which $\sigma_{e}^{2}$ is the error variance.

From these models, genetic, permanent environment, and residual variance parameters were obtained using ASReml 3.0 software (Gilmour et al., 2009). Genetic variances thus obtained were used to derive genetic variances for each week of lactation, using the method described by Kirkpatrick et al. (1990). Heritabilities, repeatabilities, and correlations between traits were calculated from these variances for each week of lactation. Standard errors were calculated as described by Fischer et al. (2004) and Gilmour (2008).

Heritabilities and repeatabilities for the same trait varied between models, but estimates were in agreement (Table 1). This confirms that bivariate models were sufficient to explore these parameters for this data set. Heritability for MY ranged from 0.16 (SE 0.27) to 0.65 (0.12) and for BW ranged from 0.40 (0.27) to 0.67 (0.18). Heritability for $\mathrm{CH}_{4}$ production ranged from 0.12 (SE 0.16) to 0.45 (0.11) (Figure 1). Heritabilities obtained for the 3 traits were not significant for the first 23 to 37 weeks of lactation. Lassen and Løvendahl (2016) reported heritability of 0.21 for $\mathrm{CH}_{4}$ production $(\mathrm{g} / \mathrm{d})$, estimated from the ratio of $\mathrm{CH}_{4}$ and $\mathrm{CO}_{2}$ concentrations in the breath of cows, measured during milking. Pszczola et al. (2017) reported heritability ranging from 0.23 to 0.30 , using the same technique. These heritabilities are close to the results of the current study, except for late lactation, where our study found that heritability was high. The low heritability (0.05) reported by Pickering et al. (2015) seems to disagree with all other studies, perhaps because the laser methane detector measures a different trait than does breath sampling during milking. Repeatability for $\mathrm{CH}_{4}$ production ranged from 0.50 (SE 0.19) to 0.69 (0.13) in the current study. Pszczola et al. (2017) found average repeatability over lactation of 0.25 , and Negussie et al. (2017) found repeatability for $\mathrm{CH}_{4}$ production (L/d) of 0.41 .

Genetic correlations between MY and $\mathrm{CH}_{4}$ production ranged from 0.38 (SE 0.42) to $0.57(0.52)$ and were significant for wk 35 to 52 in lactation (Figure 2). Lassen and Løvendahl (2016) reported a correlation of $0.43(0.10)$ between fat- and protein-corrected milk and $\mathrm{CH}_{4}$ production $(\mathrm{g} / \mathrm{d})$, using a linear animal model. From a biological point of view, these correlations are as expected. At the beginning of lactation, cows enter a negative energy balance. Body energy, rather than energy from DMI, is used for milk production. Therefore, in early lactation, the correlation between $\mathrm{MY}$ and $\mathrm{CH}_{4}$ production can be negative because no $\mathrm{CH}_{4}$ is produced from the body energy thus used. Later in lactation, energy for milk production originates from DMI, resulting in $\mathrm{CH}_{4}$ production. This leads to positive correlations between $\mathrm{MY}$ and $\mathrm{CH}_{4}$ production.

Table 1. Heritability and repeatability ranges resulting from bivariate analyses for week of lactation 1 to 52 , for milk yield (MY), BW, and $\mathrm{CH}_{4}$ production $\left(\mathrm{CH}_{4}\right)$

\begin{tabular}{llcc}
\hline Bivariate & & Heritability (SE) & Repeatability (SE) \\
\hline $\mathrm{MY}$ & $\mathrm{BW}$ & $0.18(0.27)-0.65(0.12)^{1}$ & $0.80(0.34)-0.91(0.17)$ \\
& $\mathrm{CH}_{4}$ & $0.16(0.27)-0.65(0.12)^{1}$ & $0.78(0.34)-0.91(0.16)$ \\
$\mathrm{BW}$ & $\mathrm{MY}$ & $0.48(0.27)-0.67(0.18)^{2}$ & $0.93(0.38)-0.96(0.24)$ \\
& $\mathrm{CH}_{4}$ & $0.40(0.27)-0.64(0.17)^{3}$ & $0.93(0.38)-0.96(0.23)$ \\
$\mathrm{CH}_{4}$ & $\mathrm{MY}$ & $0.12(0.16)-0.45(0.11)^{4}$ & $0.50(0.19)-0.69(0.13)$ \\
& $\mathrm{BW}$ & $0.12(0.16)-0.40(0.11)^{4}$ & $0.50(0.19)-0.66(0.14)$ \\
\hline
\end{tabular}

${ }^{1}$ Significant for week of lactation (WOL) 33-52.

${ }^{2}$ Significant for WOL 24 to 52 .

${ }^{3}$ Significant for WOL 38 to 52 .

${ }^{4}$ Significant for WOL 37 to 52 . 


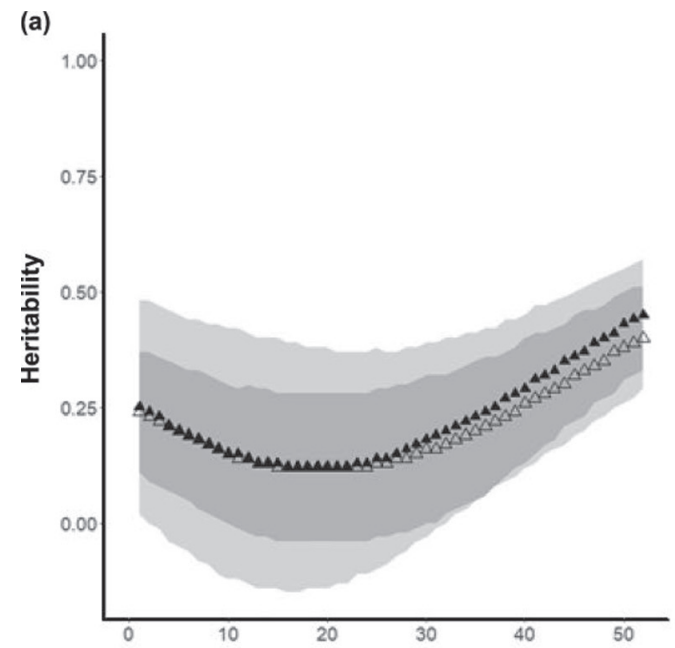

(b)

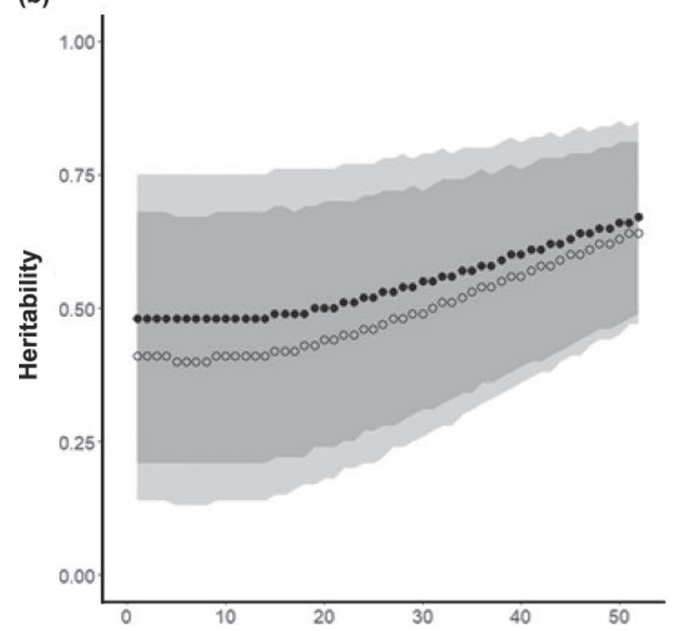

(c)

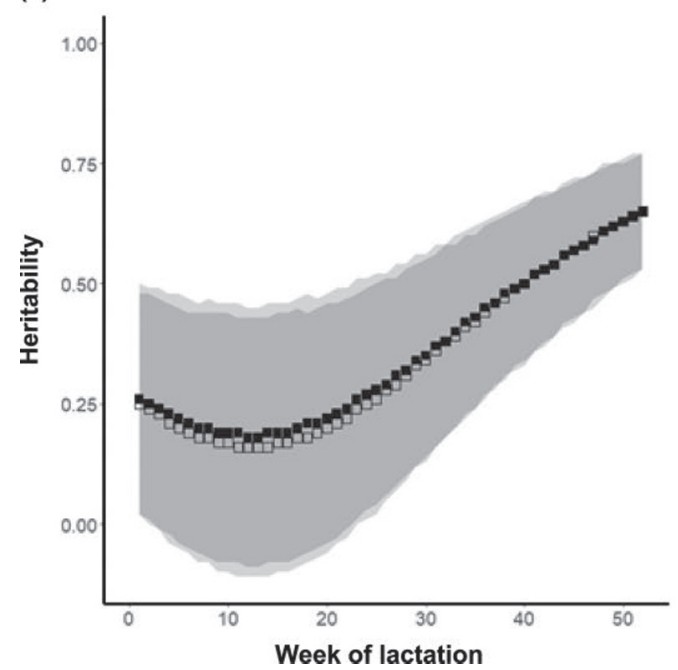

Figure 1. Heritabilities for (a) $\mathrm{CH}_{4}$ production $\left(\mathrm{CH}_{4}\right.$; $\boldsymbol{\Delta}$ for bivariate with MY, $\triangle$ for bivariate with $\mathrm{BW}$ ), (b) body weight (BW; for bivariate with MY, $\bigcirc$ for bivariate with $\mathrm{CH}_{4}$ ), and (c) milk yield (MY; - for bivariate with BW, $\square$ for bivariate with $\mathrm{CH}_{4}$ ) over week of lactation. Shaded areas reflect SE for each analysis.
Genetic correlations between $\mathrm{BW}$ and $\mathrm{CH}_{4}$ production ranged from 0.01 (SE 0.43) to 0.02 (0.65) and were not significant for any point in lactation. Lassen and Løvendahl (2016) reported a correlation of -0.18 (SE 0.08) between live weight and $\mathrm{CH}_{4}$ production $(\mathrm{g} / \mathrm{d})$, using a linear animal model. From a biological point of view, both positive and negative correlations are possible. Taking into account the whole lifetime of the cow, initial BW is low and increases to a certain stable level. Higher BW corresponds with higher feed intake, causing $\mathrm{CH}_{4}$ production to increase as well (Garnsworthy et al., 2012b). This results in a positive correlation between $\mathrm{BW}$ and $\mathrm{CH}_{4}$ production. However, BW decreases at the beginning of lactation, after which BW increases again. Feed intake peaks in mid-lactation and slowly declines toward the end of lactation (Moran, 2005). Due to the positive correlation between $\mathrm{CH}_{4}$ production and feed intake, $\mathrm{CH}_{4}$ production follows the same curve (Donoghue et al., 2016). This results in a negative correlation between $\mathrm{BW}$ and $\mathrm{CH}_{4}$ production. The current study found a correlation of almost zero, indicating that these 2 mechanisms cancelled each other out in this herd.

This study confirmed that $\mathrm{CH}_{4}$ production is moderately heritable, and therefore it is possible to select cows genetically for lower $\mathrm{CH}_{4}$ production. The positive correlation between $\mathrm{CH}_{4}$ production and MY indicated

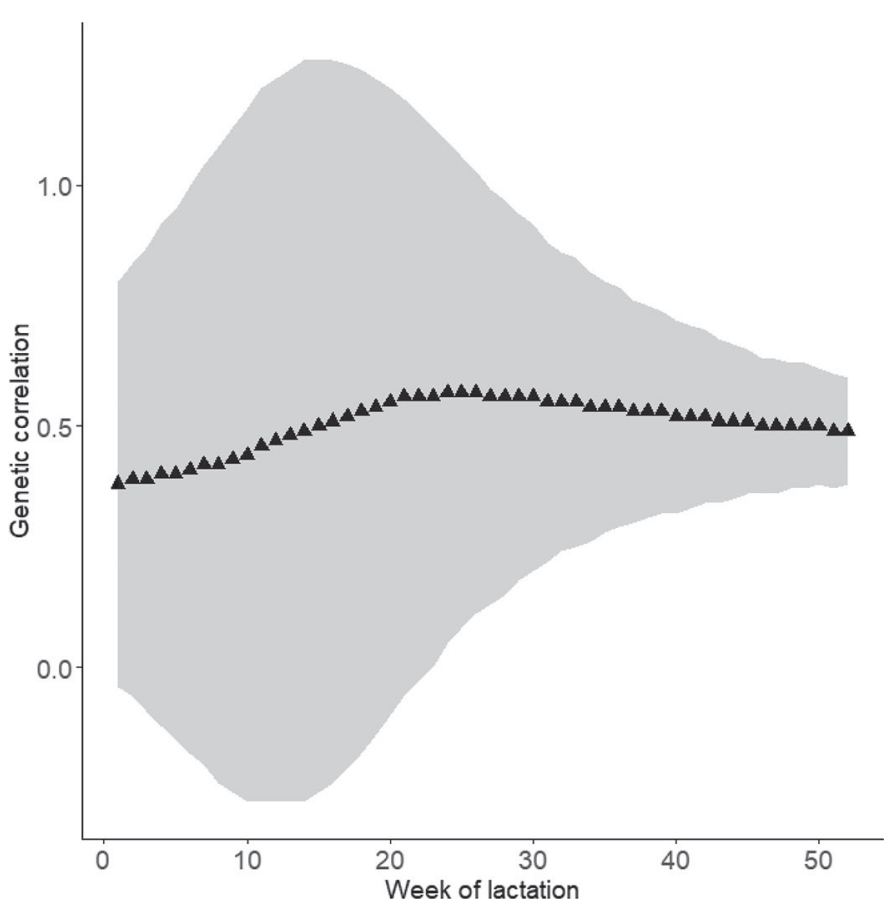

Figure 2. Genetic correlation between milk yield (MY) and $\mathrm{CH}_{4}$ production $\left(\mathrm{CH}_{4}\right)$, originating from bivariate random regression analysis. Shaded area reflects SE. 
that care must be taken that, when selecting for lower $\mathrm{CH}_{4}$ production, milk production is not reduced concurrently. To maximize reduction in $\mathrm{CH}_{4}$ production and limit associated effects in related traits, both $\mathrm{CH}_{4}$ production and MY should be included as part of a selection index in national breeding goals.

\section{ACKNOWLEDGMENTS}

I. S. Breider was supported by a Nottingham University-Scotland's Rural College joint studentship. Collection of original methane data was funded by the Department for Environment, Food and Rural Affairs (London, UK; Project AC0219). We thank R. Stöger, J. Craigon (University of Nottingham, Nottingham, UK), and E. Strandberg (Swedish University of Agricultural Sciences, Uppsala, Sweden) for valuable discussions during the study. We acknowledge J. Craigon, J. H. Hernandez-Medrano, and N. Saunders (University of Nottingham, Nottingham, UK) for collection of the original methane data.

\section{REFERENCES}

Basarab, J. A., K. A. Beauchemin, V. S. Baron, K. H. Ominski, L. L. Guan, S. P. Miller, and J. J. Crowley. 2013. Reducing GHG emissions through genetic improvement for feed efficiency: Effects on economically important traits and enteric methane production. Animal 7:303-315. https://doi.org/10.1017/S1751731113000888.

Berry, D. P., and J. J. Crowley. 2013. Genetics of feed efficiency in dairy and beef cattle. J. Anim. Sci. 91:1594-1613. https://doi.org/ 10.2527/jas.2012-5862.

Donoghue, K. A., T. Bird-Gardiner, P. F. Arthur, R. M. Herd, and R. F. Hegarty. 2016. Genetic and phenotypic variance and covariance components for methane emission and postweaning traits in Angus cattle. J. Anim. Sci. 94:1438-1445. https://doi.org/10.2527/ jas.2015-0065.

Fischer, T. M., A. R. Gilmour, and J. H. van der Werf. 2004. Computing approximate standard errors for genetic parameters derived from random regression models fitted by average information REML. Genet. Sel. Evol. 36:363-369. https://doi.org/10.1051/gse: 2004006.

Garnsworthy, P. C., J. Craigon, J. H. Hernandez-Medrano, and N. Saunders. 2012a. On-farm methane measurements during milking correlate with total methane production by individual dairy cows. J. Dairy Sci. 95:3166-3180. https://doi.org/10.3168/jds.2011-4605.

Garnsworthy, P. C., J. Craigon, J. H. Hernandez-Medrano, and N. Saunders. 2012b. Variation among individual dairy cows in methane measurements made on farm during milking. J. Dairy Sci. 95:3181-3189. https://doi.org/10.3168/jds.2011-4606.

Gerber, P. J., H. Steinfeld, B. Henderson, A. Mottet, C. Opio, J. Dijkman, A. Falcucci, and G. Tempio. 2013. Tackling Climate Change Through Livestock: A Global Assessment of Emissions and Miti- gation Opportunities. Food and Agriculture Organization of the United Nations (FAO), Rome, Italy.

Gilmour, A. R. 2008. The Standard Error of Heritability. Accessed Aug. 3, 2018. http://www.cargovale.com.au/ASReml/seherit.htm.

Gilmour, A. R., B. J. Gogel, B. R. Cullis, and R. Thompson. 2009. ASReml User Guide. Release 3.0. VSN International Ltd., Hemel Hempstead, UK.

Herd, R., S. Bird, K. Donoghue, P. Arthur, and R. Hegarty. 2013. Phenotypic associations between methane production traits, volatile fatty acids and animal breeding traits. Pages 286-289 in Proc. 10th World Conference on Genetics Applied to Livestock Production (WCGALP), Vancouver, Canada. Am. Soc. Anim. Sci., Champaign, IL.

Jamrozik, J., and L. R. Schaeffer. 1997. Estimates of genetic parameters for a test day model with random regressions for yield traits of first lactation Holsteins. J. Dairy Sci. 80:762-770. https://doi .org/10.3168/jds.S0022-0302(97)75996-4.

Kirkpatrick, M., W. Hill, and R. Thompson. 1994. Estimating the covariance structure of traits during growth and ageing, illustrated with lactation in dairy cattle. Genet. Res. 64:57-69. https://doi .org/10.1017/S0016672300032559.

Kirkpatrick, M., D. Lofsvold, and M. Bulmer. 1990. Analysis of the inheritance, selection and evolution of growth trajectories. Genetics 124:979-993.

Lassen, J., and P. Løvendahl. 2016. Heritability estimates for enteric methane emissions from Holstein cattle measured using noninvasive methods. J. Dairy Sci. 99:1959-1967. https://doi.org/10 .3168/jds.2015-10012.

Moran, J. 2005. Chapter 7: How feed requirements change during lactation. Pages 61-64 in Tropical Dairy Farming: Feeding Management for Small Holder Dairy Farmers in the Humid Tropics. Landlinks Press, Melbourne, Australia.

Morrissey, M. B., and A. J. Wilson. 2010. pedantics: An R package for pedigree-based genetic simulation, and pedigree manipulation, characterisation and viewing. Mol. Ecol. Resour. 10:711-719. https://doi.org/10.1111/j.1755-0998.2009.02817.x.

Mrode, R. A. 2005. Linear Models for the Prediction of Animal Breeding Values. 2nd ed. CABI Publishing, Wallingford, UK. https:// doi.org/10.1079/9781780643915.0000

Myhre, G., D. Shindell, F.-M. Bréon, W. Collins, J. Fuglestvedt, J. Huang, D. Koch, J.-F. Lamarque, D. Lee, B. Mendoza, T. Nakajima, A. Robock, G. Stephens, T. Takemura, and H. Zhan. 2013. Anthropogenic and natural radiative forcing. In Climate Change 2013: The Physical Science Basis. Contribution of Working Group I to the Fifth Assessment Report of the Intergovernmental Panel on Climate Change.

Negussie, E., J. Lehtinen, P. Mäntysaari, A. Bayat, A. Liinamo, E. Mäntysaari, and M. Lidauer. 2017. Non-invasive individual methane measurement in dairy cows. Animal 11:890-899. https://doi .org/10.1017/S1751731116002718.

Pickering, N. K., M. G. G. Chagunda, G. Banos, R. Mrode, J. C. McEwan, and E. Wall. 2015. Genetic parameters for predicted methane production and laser methane detector measurements. J. Anim. Sci. 93:11-20. https://doi.org/10.2527/jas.2014-8302.

Pryce, J. E., W. J. Wales, Y. De Haas, R. F. Veerkamp, and B. J. Hayes. 2014. Genomic selection for feed efficiency in dairy cattle. Animal 8:1-10. https://doi.org/10.1017/S1751731113001687.

Pszczola, M., K. Rzewuska, S. Mucha, and T. Strabel. 2017. Heritability of methane emissions from dairy cows over a lactation measured on commercial farms. J. Anim. Sci. 95:4813-4819. https: //doi.org/10.2527/jas2017.1842. 